\title{
Oridonin inhibits the proliferation of human colon cancer cells by upregulating BMP7 to activate p38 MAPK
}

\author{
CHUN-MEI REN ${ }^{1,2}$, YANG LI ${ }^{1,2}$, QIAN-ZHAO CHEN ${ }^{1,2}$, YU-HUA ZENG ${ }^{1,2}$, YING SHAO ${ }^{1,2}$, QIU-XIANG WU $^{1,2}$, \\ SHUANG-XUE YUAN ${ }^{1,2}$, JUN-QIN YANG $^{1,2}$, YU YU $^{1,3}, \mathrm{KE} \mathrm{WU}^{1,2}$, BAI-CHENG HE $^{1,2}$ and WEN-JUAN SUN ${ }^{1,2}$ \\ ${ }^{1}$ Chongqing Municipal Key Laboratory of Higher Education Institutions for Biochemistry and Molecular Pharmacology; \\ Departments of ${ }^{2}$ Pharmacology and ${ }^{3}$ Chemistry, School of Pharmacy, Chongqing Medical University, \\ Yuzhong, Chongqing 400016, P.R. China
}

Received November 21, 2015; Accepted December 17, 2015

DOI: $10.3892 /$ or.2016.4654

\begin{abstract}
Oridonin (ORI), a diterpenoid purified from Rabdosia rubescens, has been reported as a promising chemotherapy drug for colon cancer treatment; yet, the precise mechanisms underlying this anticancer activity remain unclear. In the present study, we investigated the anticancer effect of ORI in HCT116 cells, and dissected the possible molecular mechanisms underlying this activity. With crystal violet staining, flow cytometry and western blot assay, we found that ORI effectively inhibited the proliferation and induced the apoptosis of HCT116 cells. Further analysis of the results indicated that BMP7 was greatly upregulated by ORI in the HCT116 cells, but its endogenous expression in FHC cells was apparently lower than that in the colon cancer cell lines. Exogenous expression of BMP7 inhibited the proliferation of the HCT116 cells, and substantially potentiated the anticancer effect of ORI. However, the specific antibody of BMP7 nearly abolished this anticancer activity of ORI in the HCT116 cells. Meanwhile, ORI exerted no significant effect on the level of phosphorylated Smad1/5/8 or total p38 MAPK, but greatly increased the level of phosphorylated p38 MAPK in the HCT116 cells. A p38 MAPK-specific inhibitor partly reversed the antiproliferative effect of BMP7 in the HCT116 cells, but prominently promoted the effect of the BMP7 antibody on proliferation. Exogenous expression of BMP7 increased the ORI-induced phosphorylation of p38 MAPK, while the BMP7 antibody almost abolished the ORI-elevated p38 MAPK phosphorylation. Our findings suggest that ORI may be an efficacious drug for colon cancer treatment. This anticancer activity of ORI may be mediated by upregulating BMP7 at least to increase the activation of p38 MAPK.
\end{abstract}

Correspondence to: Professor Bai-Cheng $\mathrm{He}$ or Professor Wen-Juan Sun, Department of Pharmacology, School of Pharmacy, Chongqing Medical University, 1 Yixueyuan Road, Yuzhong, Chongqing 400016, P.R. China

E-mail: hebaicheng99@yahoo.com; 894704897@qq.com

E-mail: 1115494605@qq.com

Key words: oridonin, colon cancer, proliferation inhibition, BMP7, p38 MAPK

\section{Introduction}

Colon cancer is one of the most common malignancies of the digestive system and is the leading cause of mortality from cancer worldwide (1). Treatment of colon cancer includes surgery resection, chemotherapy, radiotherapy and targeted therapy, alone or in combination. To date, chemotherapy is still the major treatment for colon cancer, yet the serious side-effects associated with chemotherapy drugs greatly reduce the life quality of the patients (2). Hence, there is a great clinical need to explore new chemotherapy drugs for colon cancer treatment with low toxicity. Natural products or their derivates are one of the major sources of chemotherapy drugs, and some have been used for cancer treatment for decades, such as vincristine, taxol and camptothecin $(3,4)$. Oridonin (ORI) is extracted from the Chinese herb Rabdosia rubescens and/or related species (5). Increasing evidence suggests that ORI is capable of inhibiting growth and inducing apoptosis in several types of cancer cells, such as breast and colon cancer, leukemia, lymphoma, pancreatic cancer and osteosarcoma $(5,6)$. Our previous study also confirmed the anticancer activity of ORI in colon cancer cells. However, the exact mechanisms underlying this effect remain unclear.

Bone morphogenetic proteins (BMPs), belonging to the TGF- $\beta$ superfamily, consist of one of the important pathways to regulate development, and aberrant signaling transduction is one of the main causes for colon cancer (7-9). It has been reported that BMP2 can inhibit the proliferation of colorectal cancer cells (10), and BMP4 can induce differentiation in colorectal cancer stem cells, as well as increase their response to chemotherapy drugs (11). BMP7, another important member of the BMP family, has been approved for the treatment of bone fracture healing and spine surgery due to its excellent osteogenic activity (12). Apart from the osteogenic differentiation activity, BMP7 is involved in brown fat cell development and thermogenesis (13). Other studies indicated that BMP7 is also implicated in cancer (14), although its role in cancer needs to be further investigated. Mitogen-activated protein kinases (MAPKs) are critical mediators for signaling transduction, and respond to a wide range of extracellular stresses such as UV radiation, hypoxia, and oxidative stress (15). p38 MAPK, one class of MAPKs, is involved in regulating cell prolifera- 
tion, apoptosis, and autophagy (15). Studies have indicated that p38 MAPK activation is involved in the anticancer effect of ORI in pancreatic cancer $(16,17)$. Various functions of BMP7 are also mediated by p38 MAPK, upregulation or suppression $(18,19)$. To date, it remains unknown whether BMP7 is associated with the anticancer activity of ORI in colon cancer cells.

In the present study, we investigated the anticancer effect of ORI in colon cancer, and dissected the possible mechanisms underlying this anticancer activity of ORI in human colon cancer cells.

\section{Materials and methods}

Chemicals and drug preparations. ORI was obtained from Hao-Xuan Bio-Tech Co., Ltd. (Xi'an, China). The HCT116 cell line was obtained from the American Type Culture Collection (ATCC; Manassas, VA, USA). ORI was prepared with dimethyl sulfoxide (DMSO) or $0.4 \%$ carboxymethylcellulose sodium (CMC-Na) as a suspension for the in vitro or in vivo experiments, respectively. The p38 MAPK inhibitor SB203580 (\#S1076) was obtained from Selleckchem (Houston, TX, USA). All antibodies were purchased from Santa Cruz Biotechnology (Santa Cruz, CA, USA). Cells were cultured in Dulbecco's modified Eagle's medium (DMEM) with $10 \%$ fetal bovine serum (FBS), $100 \mathrm{U} / \mathrm{ml}$ of penicillin and $100 \mu \mathrm{g} / \mathrm{ml}$ of streptomycin at $37^{\circ} \mathrm{C}$ in $5 \% \mathrm{CO}_{2}$.

Cell proliferation and viability assays. Cell proliferation and viability were assessed with the crystal violet staining assay. HCT116 cells were plated in a 24-well plate and then treated with different concentrations of ORI; DMSO was used as a solvent control. The cells were washed carefully with cold $\left(4^{\circ} \mathrm{C}\right)$ phosphate-buffered saline (PBS) and stained with $0.5 \%$ crystal violet formalin solution at room temperature. For quantification, the crystal violet was dissolved with $1 \mathrm{ml} \mathrm{20 \%}$ acetic acid at room temperature for $20 \mathrm{~min}$ with shaking. The absorbance at $570 \mathrm{~nm}$ was then measured. Each assay was carried out in triplicate.

Construction of the BMP7 recombinant adenovirus. Recombinant adenoviruses expressing BMP7 were constructed with the AdEasy system (20), tagged with green fluorescence protein (GFP) and designated as AdBMP7. The recombinant adenovirus expressing GFP only was used as a vector control.

Flow cytometric analysis of apoptosis and cell cycle distribution. HCT116 cells were plated in a 6-well plate. The cells were treated with different concentrations of ORI or DMSO. Then, the cells were harvested and washed with cold PBS, followed by incubating with Annexin V-EGFP and propidium iodide (PI) following the instructions in the kits (KeyGen Biotech, Nanjing, China). Then, the cells were analyzed by fluorescence-activated cell sorting (FACS) for apoptosis. For the cell cycle assay, HCT116 cells were treated with different concentrations of ORI or DMSO. At $48 \mathrm{~h}$ after treatment, the cells were collected and washed with PBS, fixed with cold $\left(4^{\circ} \mathrm{C}\right) 70 \%$ ethanol, and washed with $50 \%, 30 \%$ ethanol and PBS, successively. Then, the cells were stained with $1 \mathrm{ml}$ of PI
(20 mg/ml) containing RNase $(1 \mathrm{mg} / \mathrm{ml})$ in PBS for $30 \mathrm{~min}$, and subjected to FACS analysis. Each assay was carried out in triplicate.

Reverse transcription and polymerase chain reaction analysis (RT-PCR). Subconfluent HCT116 cells were plated in T25 flasks and treated with different concentrations of ORI or DMSO. Total RNA was extracted with TRIzol reagent (Invitrogen, USA) and subjected to RT reaction to generate cDNA. Then, the cDNA was used as a template for detecting the expression level of target genes with PCR. The primer sequences are available upon request. Each assay was carried out in triplicate.

Western blot assay. HCT116 cells were plated in a 6-well plate and treated with different concentrations of ORI or DMSO. The medium was discarded, and the cells were washed with cold PBS. The cells were lysed with $300 \mu \mathrm{l}$ lysis buffer in each well, and the lysate was boiled for $10 \mathrm{~min}$. Then, the samples were subjected to SDS-PAGE separation and transferred to polyvinylidene fluoride (PVDF) membranes, which were immunoblotted with primary antibodies and HRP-conjugated secondary antibodies sequentially. The target proteins were developed with SuperSignal West Pico Substrate (Pierce, Rockford, IL, USA). Each assay was carried out in triplicate.

Statistical analysis. All quantitative data are expressed as mean \pm SD. Statistical significance between vehicle vs. drug treatment was determined by the Student's t-test. A value of $\mathrm{p}<0.05$ was considered to indicate a statistically significant result.

\section{Results}

ORI inhibits the proliferation of HCT116 cells. Evidence indicates that ORI shows an antiproliferative effect in various types of cancer cells. Thus, we tested this effect of ORI on HCT116 cells to validate whether ORI could be used as a chemotherapeutic drug for human colon cancer. The crystal violet staining assay results showed that ORI effectively inhibited the proliferation of the HCT116 cells in a time- and concentration-dependent manner (Fig. 1A). Cell cycle analysis results showed that ORI induced cell cycle arrest at the G2 phase in the HCT116 cells (Fig. 1B). Western blot assay results showed that ORI also decreased the level of proliferating cell nuclear antigen (PCNA) in the HCT116 cells (Fig. 1C). These data indicate that ORI can inhibit the proliferation of HCT116 cells, and may be a potential chemotherapeutic agent for colon cancer.

ORI induces HCT116 cells to undergo apoptosis. Next, we analyzed whether ORI induces apoptosis in HCT116 cells. HCT116 cells were seeded in a 6-well plate and were treated with different concentrations of ORI or DMSO. Then, the cells were harvested for flow cytometric analysis or lysed for western blot assay. The results showed that ORI increased the percentage of apoptotic cells in a concentration-dependent manner (Fig. 2A). Western blot assay results showed that ORI notably increased the level of Bad and reduced the level of Bcl-2 in the HCT116 cells (Fig. 2B). These findings demon- 
A

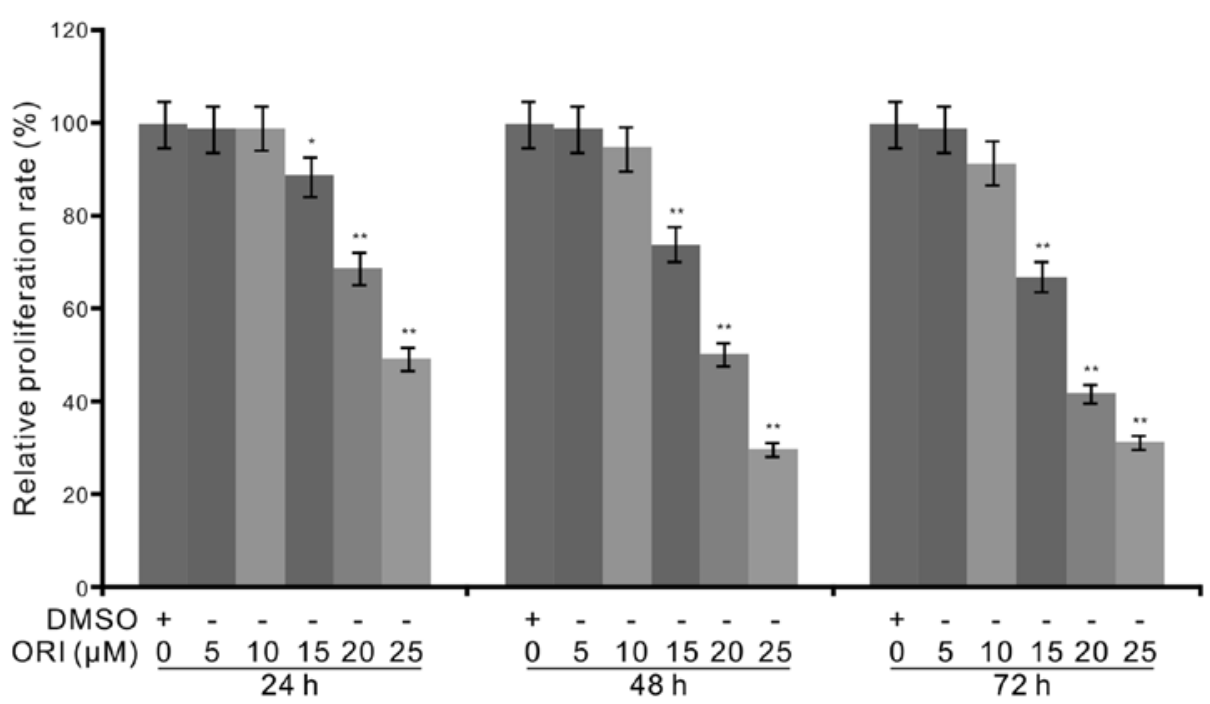

B
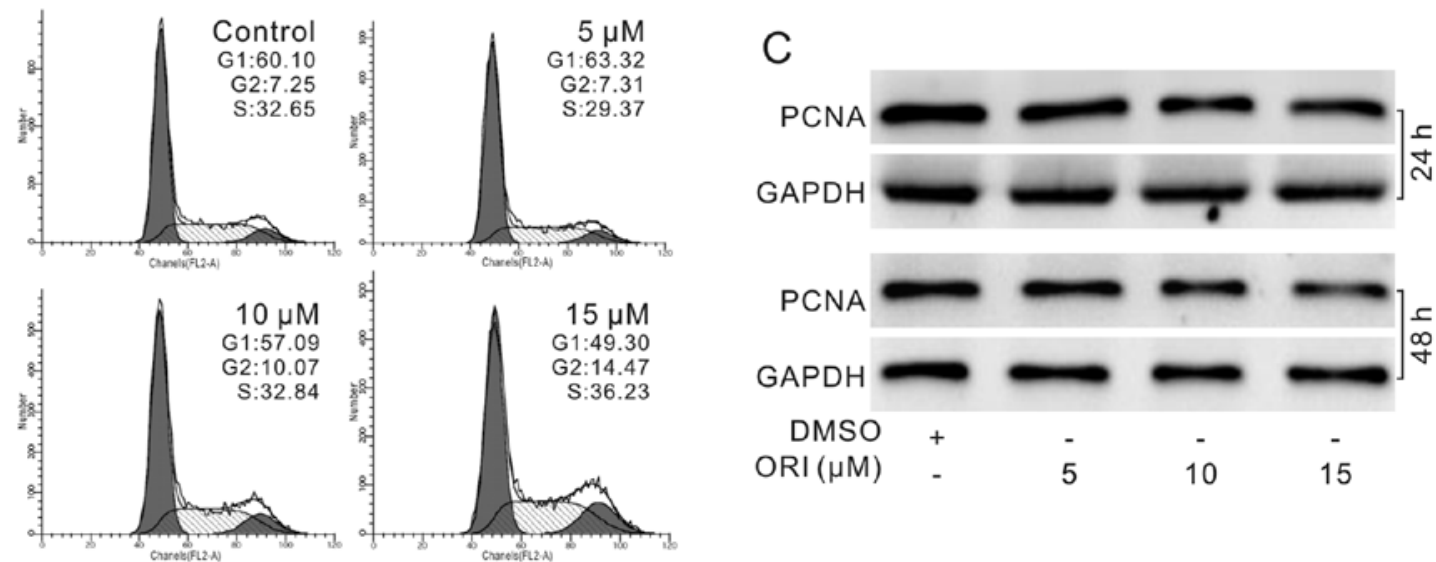

Figure 1. Effect of oridonin (ORI) on the proliferation of HCT116 cells. (A) Crystal violet staining results of the antiproliferative effect of ORI on HCT116 cells ( $\mathrm{p}<0.05$ and ${ }^{* *} \mathrm{p}<0.01$, compared with the control). (B) Flow cytometric analysis of the effect of ORI on cell cycle arrest in HCT116 cells. (C) Western blot assay of the effect of ORI on the level of PCNA in HCT116 cells. GAPDH was used as a loading control. All assay were performed in triplicate.
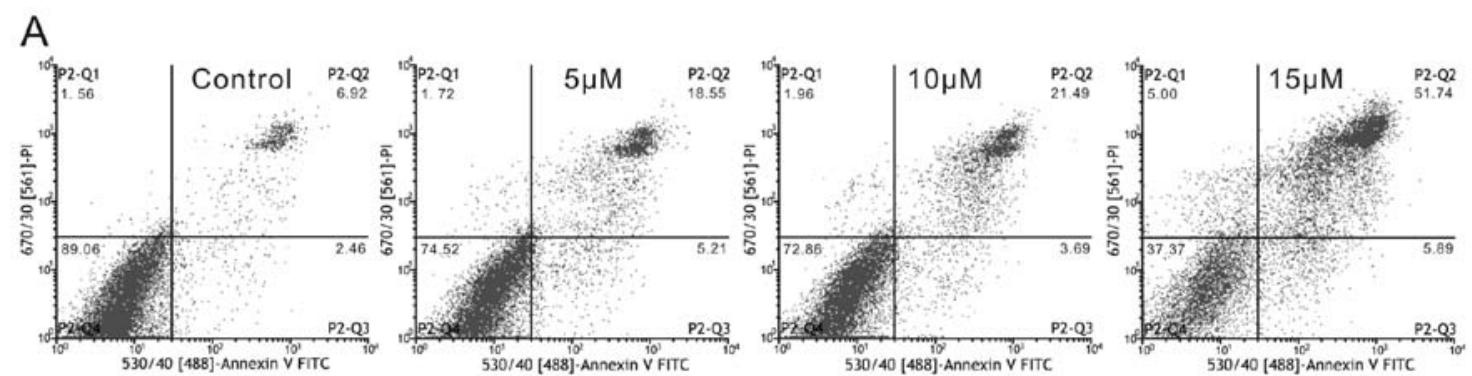

B
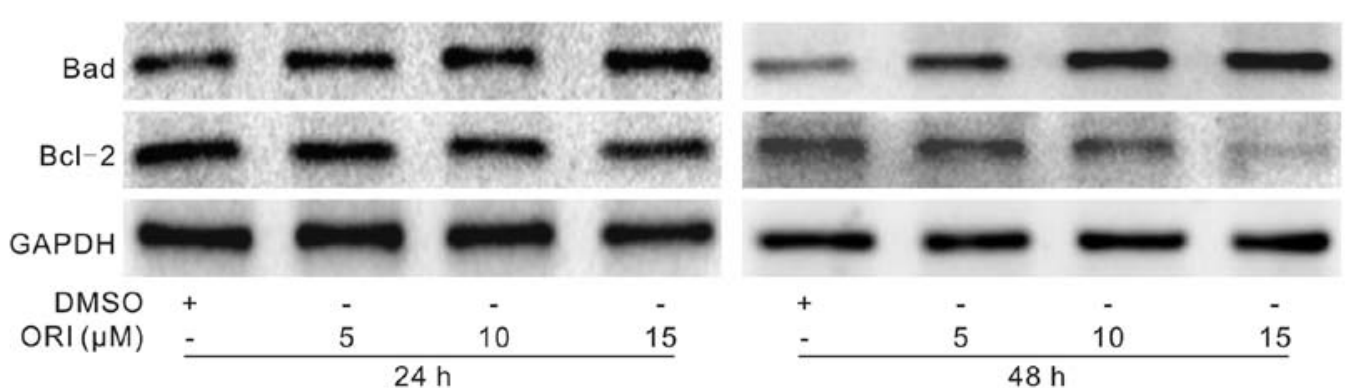

Figure 2. Effect of oridonin (ORI) on the apoptosis of HCT116 cells. (A) Flow cytometric analysis of the apoptosis induced by ORI in the HCT116 cells. (B) Western blot assay of the protein levels of Bad and Bcl-2 affected by ORI in the HCT116 cells. GAPDH was used as a loading control. All assay were performed in triplicate. 
A

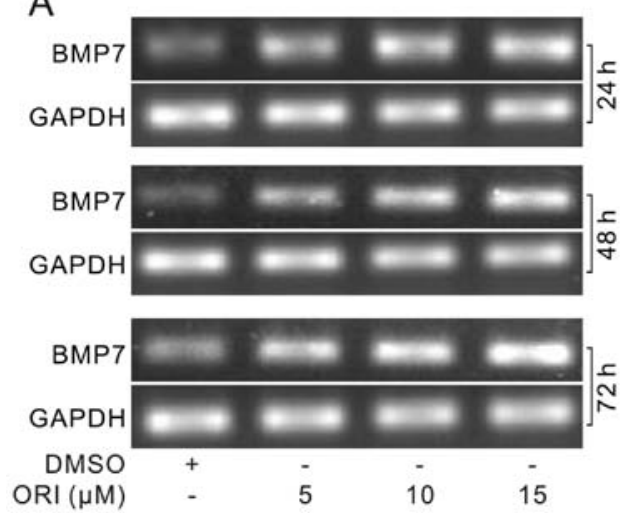

B

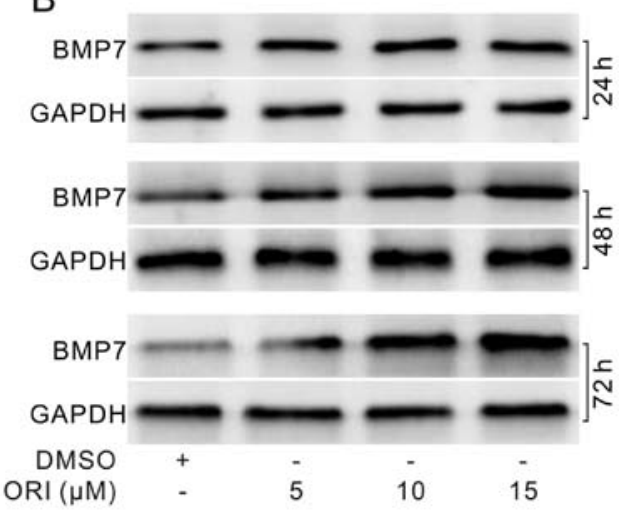

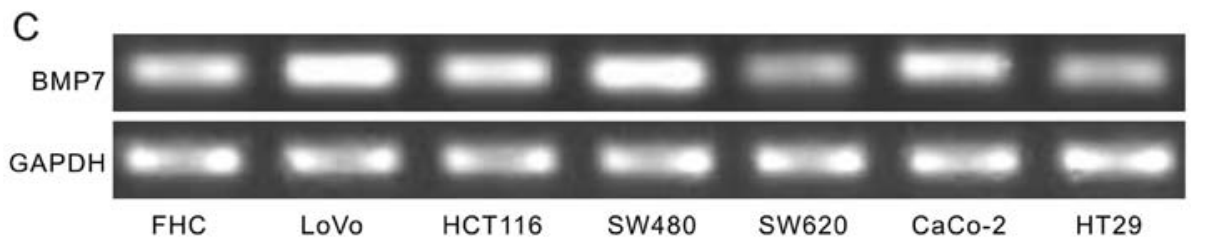

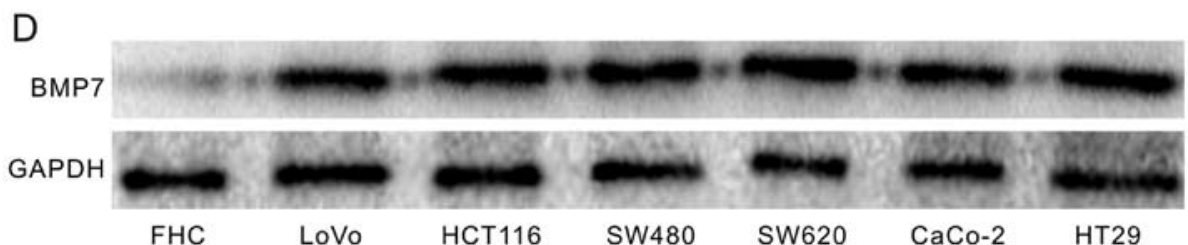

Figure 3. Effect of oridonin (ORI) on the expression of BMP7 in HCT116 cells. (A) RT-PCR assay results of the effect of ORI on the expression of BMP7 in the HCT116 cells. GAPDH was used as a loading control. (B) Western blot assay of the effect of ORI on BMP7 in the HCT116 cells. GAPDH was used as a loading control. (C) RT-PCR assay of the endogenous expression of BMP7 in commercially available colon cancer cell lines and FHC cells. GAPDH was used as a loading control. (D) Western blot assay of the endogenous level of BMP7 in commercially available colon cancer cell lines and FHC cells. GAPDH was used as a loading control.

strate that ORI may be an effective inducer of apoptosis in colon cancer cells.

ORI upregulates BMP7 in HCT116 cells. The TGF- $\beta$ signaling pathway is important for the development of the digestive system, and aberrant TGF- $\beta$ signaling is one of the main etiologies of colon cancer (21). The PCR assay results showed that ORI increased the mRNA level of BMP7 substantially (Fig. 3A). Western blot assay results confirmed that ORI increased the level of BMP7 in a concentration- and timedependent manner (Fig. 3B). Furthermore, PCR (Fig. 3C) and western blot assay results (Fig. 3D) showed that endogenous expression of BMP7 in colon cancer cell lines was higher than that in the FHC cells. These data demonstrate that ORI can upregulate BMP7, and it may play an essential role in the antiproliferative effect of ORI in colon cancer cells.

BMP7 partly mediates the antiproliferative effect of ORI in HCT116 cells. We next investigated the influence of BMP7 on the antiproliferative effect of ORI in colon cancer cells. We introduced recombinant adenoviruses of BMP7 (AdBMP7) for exogenous expression of BMP7 and the BMP7-specific antibody for BMP7 immunodepletion. The results showed that exogenous expression of BMP7 inhibited the proliferation of the HCT116 cells (Fig. 4A). Crystal violet staining analysis results indicated that ORI combined with exogenous expression of BMP7 substantially enhanced the antiproliferative effect of ORI, while the BMP7 antibody
(4 ng/ml) antibody almost reversed the antiproliferative effect of ORI $(10 \mu \mathrm{M})$ in the HCT116 cells (Fig. 4B). Further results showed that exogenous expression of BMP7 increased the protein level of Bad upregulated by ORI, but potentiated the effect of ORI on decreasing the level of Bcl-2; on the contrary, the BMP7 antibody attenuated the effects of ORI on Bad and Bcl-2, respectively (Fig. 4C). These results indicate that upregulation of BMP7 may mediate the antiproliferative effect of ORI in colon cancer cells.

p38 MAPK mediates the antiproliferative effect of BMP7 in HCT116 cells. Although exogenous expression of BMP7 enhanced the antiproliferative effect of ORI in HCT116 cells, the mechanisms which mediated this effect remain unknown. Western blot analysis showed that ORI exerted no substantial effect on the phosphorylation of Smad1/5/8 (p-Smad1/5/8), but increased the phosphorylation of p38 MAPK (p-p38) in a concentration-dependent manner (Fig. 5A). These results indicate that the antiproliferative effect of ORI may not be mediated by BMP7 through canonical BMP/Smad signaling at least. Further crystal violet staining assay results showed that the p38 MAPK inhibitor (SB203580, SB) promoted the proliferation of HCT116 cells, attenuated the antiproliferative effect of BMP7, and synergistically enhanced the proliferation of HCT116 cells when combined with the BMP7 antibody (Fig. 5B). These data imply that p38 MAPK may be critical for BMP7 to mediate the antiproliferative effect of ORI in HCT116 cells. The subsequent western blot assay 


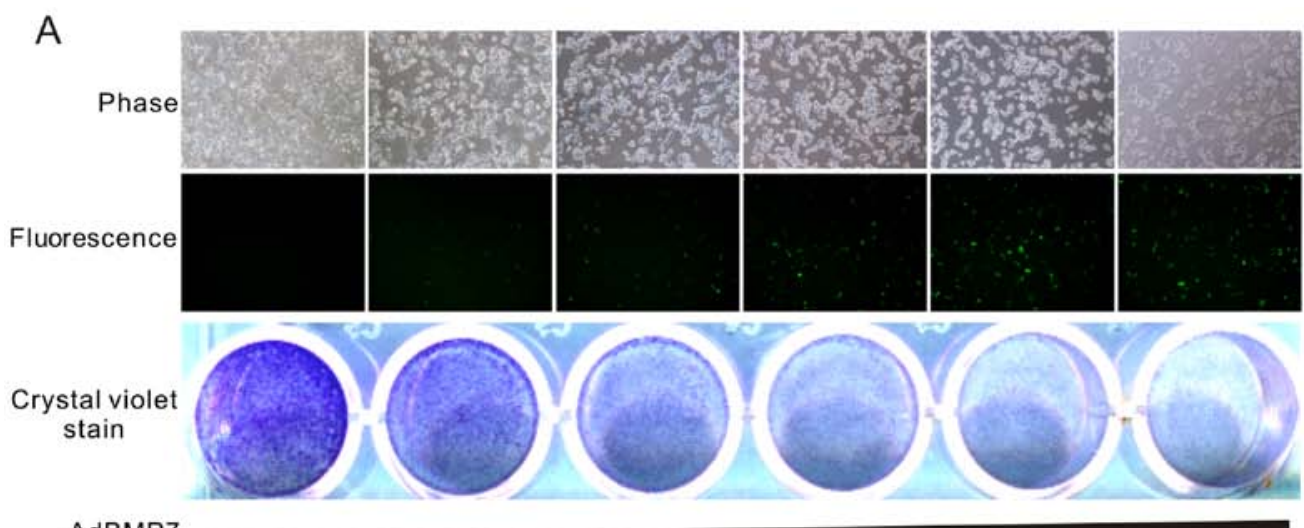

AdBMP7

B

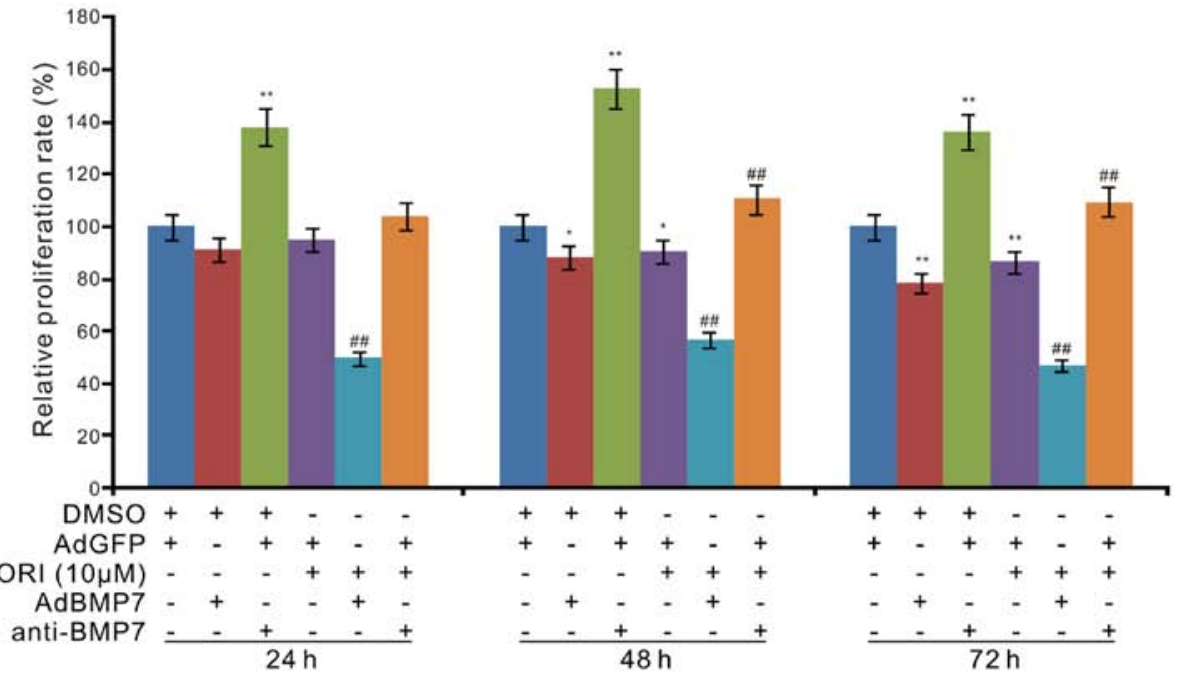

C
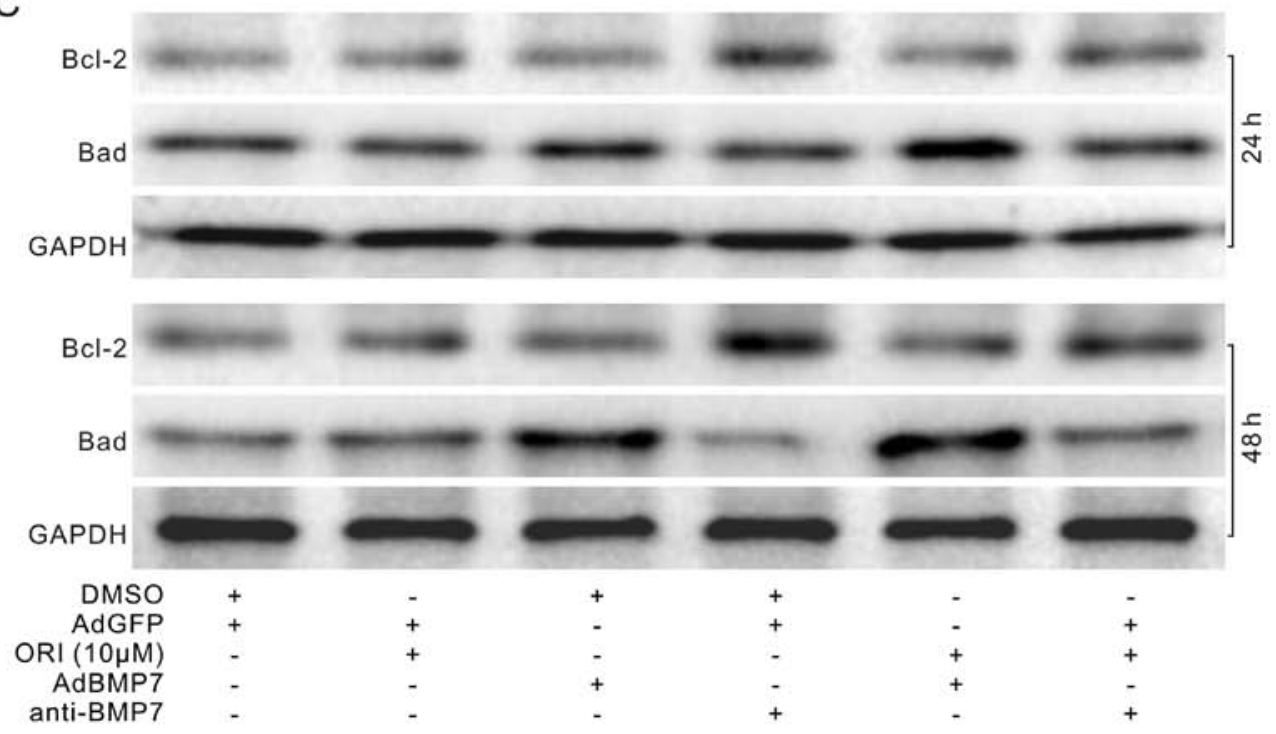

Figure 4. Effects of BMP7 on the anticancer activity of ORI in HCT116 cells. (A) Crystal violet staining results of the effect of BMP7 on the proliferation of the HCT116 cells. The upper panel shows the phase images of the HCT116 cells, the middle panel shows the infection results of the BMP7 recombinant adenovirus, and the lower panel shows the crystal violet staining results. (B) Quantification of the crystal violet staining results of the effect of BMP7 or the BMP7 antibody on the antiproliferative effect of ORI in the HCT116 cells ( $\mathrm{p}<0.05$ and ${ }^{* *} \mathrm{p}<0.01$, compared with the control; ${ }^{* \#} \mathrm{p}<0.01$, compared with the ORI-treated group). (C) Western blot assay of the effect of BMP7 or the BMP7 antibody on the levels of Bcl-2 and Bad affected by ORI in the HCT116 cells. GAPDH was used as a loading control. All assays were performed in triplicate.

results showed that BMP7 increased p38 MAPK phosphorylation, and the BMP7 antibody apparently inhibited p38 MAPK phosphorylation. The combination of BMP7 and ORI markedly increased the level of p38 MAPK phosphorylation, while the BMP7 antibody combined with ORI decreased it apparently (Fig. 5C). These results indicated that BMP7 may mediate the antiproliferative effect of ORI in part by activating p38 MAPK signaling. 

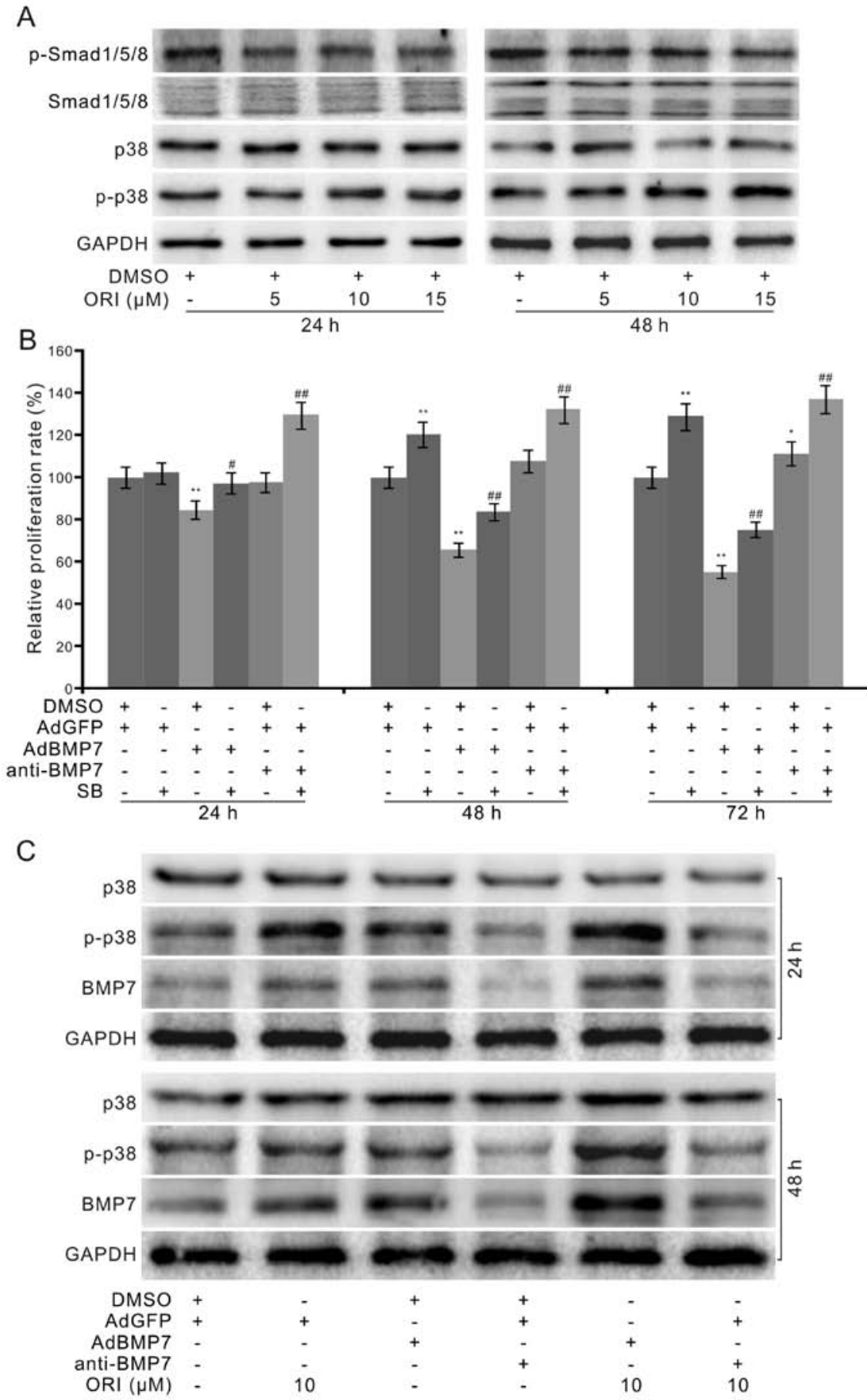

Figure 5. Effects of the BMP7-mediated antiproliferative effect of ORI on p38 MAPK in colon cancer. (A) Western blot assay of the effect of ORI on the levels of Smad1/5/8, p-Smad1/5/8, p38 MAPK or p-p38 MAPK in the HCT116 cells. GAPDH was used as a loading control. (B) Quantification of crystal violet staining results of the effect of the p38 MAPK-specific inhibitor (SB) on the proliferative affected by exogenous BMP7 or the BMP7 antibody in the HCT116 cells ( ${ }^{*} \mathrm{p}<0.05$ and ${ }^{* *} \mathrm{p}<0.01$, compared with the control; ${ }^{\#} \mathrm{p}<0.05$ and ${ }^{\# \#} \mathrm{p}<0.01$, compared with the BMP7 recombinant adenovirus or the BMP7 antibody group). SB, p38 MAPK inhibitor, SB203580. (C) Western blot assay of the effect of exogenous BMP7 or the BMP7 antibody on the level of p38 MAPK or p-p38 MAPK affected by ORI in HCT116 cells. GAPDH was used as a loading control. All assays were performed in triplicate.

\section{Discussion}

In the present study, we demonstrated that ORI may be an excellent candidate chemotherapeutic agent for colon cancer treatment. Mechanistically, we found that the anticancer activity of ORI may be mediated though the upregulation of BMP7 to activate p38 MAPK signaling.

ORI is extracted from the Chinese traditional medicinal herb Rabdosia rubescens. As a diterpenoid compound, ORI exhibits various pharmacological functions and has been used for many years as an antitumor, anti-microbial, antiinflammatory and antioxidant agent (5). Studies indicate that ORI exhibits antiproliferation and apoptosis-inducing effects in many types of cancer cells, such as lymphoma, breast cancer, leukemia, colon and lung cancer (22-26). The present study also demonstrated this anticancer effect of ORI in colon cancer cells. Several molecular mechanisms have been reported to be involved in this effect, such as blockage 
of extracellular signal-regulated kinase (ERK) and PI3K/ Akt, activation of p53 and p38 MAPK, increase in hydrogen peroxide and suppression of $\mathrm{Wnt} / \beta$-catenin signaling $(6,16$, 26-28). However, to date, the precise mechanisms mediating the anticancer activity of ORI remain unclear.

The pathogenesis of colon cancer includes the aberrant transduction of various signaling pathways, such as TGF- $\beta$, Wnt/ $\beta$-catenin, PI3K/Akt $(21,29)$. BMP7 belongs to the TGF- $\beta$ superfamily and is also known as osteogenic protein-1 (OP-1). It was discovered by Marshal Urist in 1965. As one of the members of the BMPs, BMP7 can effectively commit the precursor cells to osteoblastic lineage. The FDA has approved the clinical usage of BMP7 for the treatment of bone-related disease, such as bone fracture healing and spine surgery (12). Besides osteogenic differentiation, BMP7 has many other physiological functions, such as the regulation of brown fat cells (13) and appetite (30). In fact, it has been reported that the expression of BMP7 is associated with cancer development, metastasis and invasion (31-35). BMP7 inhibits TGF 31 -related epithelial-mesenchymal transition (EMT) in breast cancer cells (36), but induces EMT in prostate cancer cells (37). Expression of BMP7 was found to be higher in cancerous tissues than that in normal tissues, and a high level of BMP7 is related with the recurrence of bladder cancer (31), poor prognosis in hepatocellular carcinoma $(32,38)$, secondary drug-resistance in mantle cell lymphoma (39), and bone metastasis of lung cancer (34). BMP7 may also be a target for MYC to promote cell survival in childhood medulloblastoma (40). BMP7 was detectable in about $50 \%$ of gastric cancer, and may be used as a strong marker for tumor recurrence (33). Hence, BMP7 may be a potential target for cancer treatment. However, it was also reported that BMP7 exerts a protective effect in intestinal epithelial cells from lesions of precancerous and inflammatory bowel diseases (14), and suppresses the growth of colon cancer cells in a Smad4-dependent-manner (9). Therefore, the role of BMP7 in colon cancer is controversial, and may be different in specific cell types and the microenvironment. Our data showed that the expression of BMP7 in colon cancer cells was higher than that in FHC cells (Fig. 3C and D). ORI increased the level of BMP7, and exogenous expression of BMP7 enhanced the antiproliferative effect of ORI in HCT116 cells. The BMP7 antibody partly reversed the inhibitory effect of ORI on cell proliferation (Fig. 4B). Thus, our findings suggest that elevated BMP7 may mediate the antiproliferative effect of ORI in colon cancer cells.

BMP7 exerts its physiological function through the BMP/Smad pathway (41), namely canonical BMP/Smad signaling pathway, or non-canonical BMP/Smad signaling pathway, such as PI3K/Akt and MAPKs $(18,37,42)$. We found that ORI did not increase the phosphorylation of Smad1/5/8 (Fig. 5A), although BMP7 was upregulated. This finding implied that the proliferation inhibitory effect of ORI may not be mediated through the BMP/Smad signaling pathway, which is consistent with the report that BMP7 exerts the antiproliferative effect in a Smad4-independent pathway (14). It has been reported that BMP7 can activate or suppress p38 MAPK signaling $(18,19)$, and the anticancer activity of ORI may contribute to the activation of p38 MAPK (16). Thus, we speculated that the effect of BMP7 on the antiproliferative activity of ORI in colon cancer cells may be associated with p38 MAPK activation. Western blot assay showed that ORI activated p38 MAPK in the HCT116 cells (Fig. 5A). The p38 MAPK inhibitor partly reversed the growth inhibitory effect of ORI, but synergistically promoted the proliferationenhancing effect of the BMP7 antibody in the HCT116 cells (Fig. 5B). Therefore, activation of p38 MAPK may be essential for BMP7 to mediate the anticancer effect of ORI in colon cancer cells. Our further investigation demonstrated that BMP7 increased the level of p-p38 MAPK, and synergistically elevated the ORI-induced p-p38 MAPK, while the BMP7 antibody markedly decreased the level of p-p38 MAPK affected by ORI in HCT116 cells. All these data suggest that BMP7 may partly mediate the antiproliferative effect of ORI by activating p38 MAPK in colon cancer cells.

In summary, our findings demonstrated that ORI may be an excellent candidate chemotherapy drug for colon cancer. The anticancer activity of ORI may be mediated by upregulating BMP7 to activate p38 MAPK in colon cancer cells. However, the molecular mechanisms of how ORI upregulate BMP7 need to be further investigated.

\section{Acknowledgements}

We thank Professor Tong-Chuan He of the University of Chicago Medical Center (Chicago, IL, USA) for his kind provision of the recombinant adenoviruses. The present study was partly supported by a research grant from the Natural Science Foundation of China (grants no. NSFC 81372120 and 81572226 to Bai-Cheng He).

\section{References}

1. Applegate CC and Lane MA: Role of retinoids in the prevention and treatment of colorectal cancer. World J Gastrointest Oncol 7: 184-203, 2015.

2. Gustavsson B, Carlsson G, Machover D, Petrelli N, Roth A, Schmoll HJ, Tveit KM and Gibson F: A review of the evolution of systemic chemotherapy in the management of colorectal cancer. Clin Colorectal Cancer 14: 1-10, 2015.

3. Banjerdpongchai R, Chanwikruy Y, Rattanapanone V and Sripanidkulchai B: Induction of apoptosis in the human leukemic U937 cell line by Kaempferia parviflora Wall.ex.Baker extract and effects of paclitaxel and camptothecin. Asian Pac J Cancer Prev 10: 1137-1140, 2009.

4. Weaver BA: How Taxol/paclitaxel kills cancer cells. Mol Biol Cell 25: 2677-2681, 2014.

5. Owona BA and Schluesener HJ: Molecular insight in the multifunctional effects of oridonin. Drugs R D 15: 233-244, 2015.

6. Liu Y, Liu YZ, Zhang RX, Wang X, Meng ZJ, Huang J, Wu K, Luo JY, Zuo GW, Chen L, et al: Oridonin inhibits the proliferation of human osteosarcoma cells by suppressing $\mathrm{Wnt} / \beta$-catenin signaling. Int J Oncol 45: 795-803, 2014.

7. Voorneveld PW, Kodach LL, Jacobs RJ, Liv N, Zonnevylle AC, Hoogenboom JP, Biemond I, Verspaget HW, Hommes DW, de Rooij K, et al: Loss of SMAD4 alters BMP signaling to promote colorectal cancer cell metastasis via activation of Rho and ROCK. Gastroenterology 147: 196-208.e13, 2014.

8. Bertrand FE, Angus CW, Partis WJ and Sigounas G: Developmental pathways in colon cancer: Crosstalk between WNT, BMP, Hedgehog and Notch. Cell Cycle 11: 4344-4351, 2012.

9. Beck SE, Jung BH, Fiorino A, Gomez J, Rosario ED, Cabrera BL, Huang SC, Chow JY and Carethers JM: Bone morphogenetic protein signaling and growth suppression in colon cancer. Am J Physiol Gastrointest Liver Physiol 291: G135-G145, 2006.

10. Zhang Y, Chen X, Qiao M, Zhang BQ, Wang N, Zhang Z, Liao Z, Zeng L, Deng Y, Deng F, et al: Bone morphogenetic protein 2 inhibits the proliferation and growth of human colorectal cancer cells. Oncol Rep 32: 1013-1020, 2014. 
11. Lombardo Y, Scopelliti A, Cammareri P, Todaro M, Iovino F Ricci-Vitiani L, Gulotta G, Dieli F, de Maria R and Stassi G: Bone morphogenetic protein 4 induces differentiation of colorectal cancer stem cells and increases their response to chemotherapy in mice. Gastroenterology 140: 297-309, 2011.

12. Kamiya N, Ye L, Kobayashi T,Lucas DJ, Mochida Y, Yamauchi M, Kronenberg HM, Feng JQ and Mishina Y: Disruption of BMP signaling in osteoblasts through type IA receptor (BMPRIA) increases bone mass. J Bone Miner Res 23: 2007-2017, 2008.

13. Richard D and Picard F: Brown fat biology and thermogenesis. Front Biosci 16: 1233-1260, 2011.

14. Grijelmo C, Rodrigue C, Svrcek M, Bruyneel E, Hendrix A, de Wever $\mathrm{O}$ and Gespach C: Proinvasive activity of BMP-7 through SMAD4/src-independent and ERK/Rac/JNK-dependent signaling pathways in colon cancer cells. Cell Signal 19: 1722-1732, 2007.

15. Tormos AM, Taléns-Visconti R, Nebreda AR and Sastre J: p38 MAPK: A dual role in hepatocyte proliferation through reactive oxygen species. Free Radic Res 47: 905-916, 2013.

16. Bu HQ, Liu DL, Wei WT, Chen L, Huang H, Li Y and Cui JH: Oridonin induces apoptosis in SW1990 pancreatic cancer cells via p53- and caspase-dependent induction of p38 MAPK. Oncol Rep 31: 975-982, 2014.

17. Bu HQ, Luo J, Chen H, Zhang JH, Li HH, Guo HC, Wang ZH and Lin SZ: Oridonin enhances antitumor activity of gemcitabine in pancreatic cancer through MAPK-p38 signaling pathway. Int J Oncol 41: 949-958, 2012.

18. Guan J, Li H, Lv T, Chen D, Yuan Y and Qu S: Bone morphogenic protein-7 contributes to cerebral ischemic preconditioning induced-ischemic tolerance by activating p38 mitogen-activated protein kinase signaling pathway. Inflammation 37: 1289-1296, 2014.

19. Takahashi M, Otsuka F, Miyoshi T, Otani H, Goto J, Yamashita M, Ogura T, Makino H and Doihara H: Bone morphogenetic protein 6 (BMP6) and BMP7 inhibit estrogen-induced proliferation of breast cancer cells by suppressing p38 mitogen-activated protein kinase activation. J Endocrinol 199: 445-455, 2008

20. Luo J, Deng ZL, Luo X, Tang N, Song WX, Chen J, Sharff KA Luu HH, Haydon RC, Kinzler KW, et al: A protocol for rapid generation of recombinant adenoviruses using the AdEasy system. Nat Protoc 2: 1236-1247, 2007.

21. Mishra L, Shetty K, Tang Y, Stuart A and Byers SW: The role of TGF-beta and Wnt signaling in gastrointestinal stem cells and cancer. Oncogene 24: 5775-5789, 2005.

22. Liu YQ, Mu ZQ, You S, Tashiro S, Onodera S and Ikejima T: Fas/FasL signaling allows extracelluar-signal regulated kinase to regulate cytochrome $c$ release in oridonin-induced apoptotic U937 cells. Biol Pharm Bull 29: 1873-1879, 2006.

23. Hsieh TC, Wijeratne EK, Liang JY, Gunatilaka AL and Wu JM: Differential control of growth, cell cycle progression, and expression of NF- $\kappa \mathrm{B}$ in human breast cancer cells MCF-7, MCF-10A, and MDA-MB-231 by ponicidin and oridonin, diterpenoids from the Chinese herb Rabdosia rubescens. Biochem Biophys Res Commun 337: 224-231, 2005.

24. Zhou GB, Kang H, Wang L, Gao L, Liu P, Xie J, Zhang FX, Weng XQ, Shen ZX, Chen J, et al: Oridonin, a diterpenoid extracted from medicinal herbs, targets AML1-ETO fusion protein and shows potent antitumor activity with low adverse effects on $\mathrm{t}(8 ; 21)$ leukemia in vitro and in vivo. Blood 109: 3441-3450, 2007

25. Zhu Y, Xie L, Chen G, Wang H and Zhang R: Effects of oridonin on proliferation of HT29 human colon carcinoma cell lines both in vitro and in vivo in mice. Pharmazie 62: 439-444, 2007.
26. Li D, Wu LJ, Tashiro S, Onodera S and Ikejima T: Oridonininduced A431 cell apoptosis partially through blockage of the Ras/Raf/ERK signal pathway. J Pharmacol Sci 103: 56-66, 2007.

27. Hu HZ, Yang YB, Xu XD, Shen HW, Shu YM, Ren Z, Li XM, Shen HM and Zeng HT: Oridonin induces apoptosis via PI3K/Akt pathway in cervical carcinoma HeLa cell line. Acta Pharmacol Sin 28: 1819-1826, 2007.

28. Gao FH, Liu F, Wei W, Liu LB, Xu MH, Guo ZY, Li W, Jiang B and $\mathrm{Wu}$ YL: Oridonin induces apoptosis and senescence by increasing hydrogen peroxide and glutathione depletion in colorectal cancer cells. Int J Mol Med 29: 649-655, 2012.

29. Markowitz SD and Bertagnolli MM: Molecular origins of cancer: Molecular basis of colorectal cancer. N Engl J Med 361: 2449-2460, 2009.

30. Saini S, Duraisamy AJ, Bayen S, Vats P and Singh SB: Role of BMP7 in appetite regulation, adipogenesis, and energy expenditure. Endocrine 48: 405-409, 2015

31. Kuzaka B, Janiak M, Włodarski KH, Radziszewski P and Włodarski PK: Expression of bone morphogenetic protein-2 and -7 in urinary bladder cancer predicts time to tumor recurrence. Arch Med Sci 11: 378-384, 2015.

32. Li W, Cai HX, Ge XM, Li K, Xu WD and Shi WH: Prognostic significance of BMP7 as an oncogene in hepatocellular carcinoma. Tumour Biol 34: 669-674, 2013.

33. Aoki M, Ishigami S, Uenosono $\mathrm{Y}$, Arigami T, Uchikado $\mathrm{Y}$, Kita Y, Kurahara H, Matsumoto M, Ueno S and Natsugoe S: Expression of BMP-7 in human gastric cancer and its clinical significance. Br J Cancer 104: 714-718, 2011.

34. Liu Y, Chen J, Yang Y, Zhang L and Jiang WG: Molecular impact of bone morphogenetic protein 7, on lung cancer cells and its clinical significance. Int J Mol Med 29: 1016-1024, 2012.

35. Alarmo EL, Pärssinen J, Ketolainen JM, Savinainen K, Karhu R and Kallioniemi A: BMP7 influences proliferation, migration, and invasion of breast cancer cells. Cancer Lett 275: 35-43, 2009.

36. Ying X, Sun Y and He P: Bone morphogenetic protein-7 inhibits EMT-associated genes in breast cancer. Cell Physiol Biochem 37: 1271-1278, 2015.

37. Lim M, Chuong CM and Roy-Burman P: PI3K, Erk signaling in BMP7-induced epithelial-mesenchymal transition (EMT) of PC-3 prostate cancer cells in 2- and 3-dimensional cultures. Horm Cancer 2: 298-309, 2011.

38. Motoyama K, Tanaka F, Kosaka Y, Mimori K, Uetake H, Inoue $\mathrm{H}$, Sugihara K and Mori M: Clinical significance of BMP7 in human colorectal cancer. Ann Surg Oncol 15: 1530-1537, 2008.

39. Camara-Clayette V, Koscielny S, Roux S, Lamy T, Bosq J, Bernard M, Fest T, Lazar V, Lenoir G and Ribrag V: BMP7 expression correlates with secondary drug resistance in mantle cell lymphoma. PLoS One 8: e73993, 2013.

40. Fiaschetti G, Castelletti D, Zoller S, Schramm A, Schroeder C, Nagaishi M, Stearns D, Mittelbronn M, Eggert A, Westermann F, et al: Bone morphogenetic protein-7 is a MYC target with prosurvival functions in childhood medulloblastoma. Oncogene 30: 2823-2835, 2011

41. Itoh F, Asao H, Sugamura K, Heldin CH, ten Dijke P and Itoh S: Promoting bone morphogenetic protein signaling through negative regulation of inhibitory Smads. EMBO J 20: 4132-4142, 2001.

42. Greenblatt MB, Kim JM, Oh H, Park KH, Choo MK, Sano Y, Tye CE, Skobe Z, Davis RJ, Park JM, et al: p38 $\alpha$ MAPK is required for tooth morphogenesis and enamel secretion. J Biol Chem 290: 284-295, 2015. 